\title{
Benzotriazole as a Synthetic Auxiliary ${ }^{\dagger}$
}

\author{
Branka Zorc, ${ }^{*}$ Zrinka Rajić Džolić, and Tyæra Bururil \\ Faculty of Pharmacy and Biochemistry, University of Zagreb, A. Kovačića 1, HR-10000 Zagreb, Croatia \\ RECEIVED MAY 23, 2012; REVISED SEPTEMBER 24, 2012; ACCEPTED SEPTEMBER 25, 2012
}

\begin{abstract}
Benzotriazole is a very useful synthetic auxiliary with versatile applications in organic chemistry. We have used benzotriazole in the synthesis of various heterocyclic compounds (benzoxazine, quinazoline, triazinetrione, hydantoin, oxadiazine and diazepane derivatives), amino acid derivatives, carbamates, ureas, semicarbazides, carbazides, sulfonylureas, sulfonylcarbazides, hydantoic acids, nonsteroidal antiinflammatory drug (NSAID) and primaquine derivatives, polymer-drug and thiomer-drug conjugates. The results have been published in more than 30 papers and here we give an overview of all syntheses. (doi: 10.5562/cca2124)
\end{abstract}

Keywords: benzotriazole, 1-benzotriazole carboxylic acid chloride, synthesis, heterocyclic compound, amino acid, NSAID, primaquine, polymer-drug conjugate

\section{INTRODUCTION}

Benzotriazole is an aromatic five-membered heterocyclic compound condensed with benzene. It is clasified as an azole, together with pyrazole, imidazole, 1,2,3and 1,2,4-triazole, tetrazole, indazole and benzimidazole. Many years ago, H. A. Staab and collaborators systematically investigated $\mathrm{N}$-substituted azoles and found out their high reactivity. ${ }^{1,2}$ Staab considered imidazole as the most convenient azole, and 1,1'-carbonyldiimidazole (CDI) has found its use in numerous syntheses. Contrary to most other azoles, benzotriazole reacts with phosgene in a molar ratio $1: 1$, yielding 1-benzotriazole carboxylic acid choride (1-benzotriazolecarbonyl chloride, $\mathrm{BtcCl}, 1){ }^{3}$ Phosgene used in original synthetic procedure was later on replaced with triphosgene (Scheme 1). ${ }^{4}$ Today, chloride $\mathbf{1}$ is a commercially available compound.
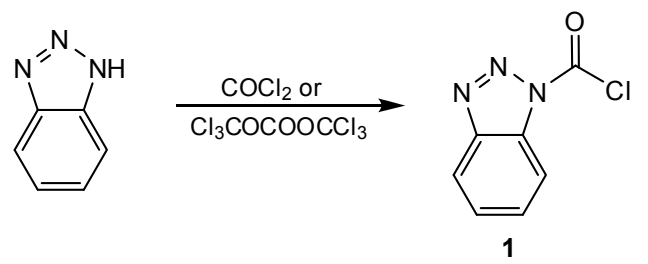

Scheme 1. Synthesis of 1-benzotriazole carboxylic acid chloride $(\mathrm{BtcCl}, \mathbf{1})$.
A. R. Katritzky gave enormous contribution to development of benzotriazole chemistry. Since 1985, he has published more than 300 papers and several reviews dealing with benzotriazole. ${ }^{5-11}$ He defined benzotriazole as a compound which fulfils all demands of an ideal synthetic auxiliary: it is inexpensive, stable, it can be introduced readily at the beginning of the reaction sequence, it is stable during various synthetic operations, it exerts an activating influence on the other parts of the molecule, it is easy to remove and can be recovered and used again. $^{12}$

Our group started with benzotriazole chemistry in 1977 and the results have been published in more than 30 papers. In this review, all the versatile reactions in which we have used benzotriazole are presented and shortly discussed.

\section{REACTIONS OF BtcCI WITH AMINO COMPOUNDS AND ALCOHOLS}

Firstly, we investigated the reaction of $\mathrm{BtcCl}$ (1) with amines, hydrazines and alcohols. Products of the reactions, 1-carbamoylbenzotriazoles $\mathbf{2}$, reactive hydrazides $\mathbf{8}$ or carbamates $\mathbf{1 1}$ reacted readily with amino compounds when appropriate reaction conditions were applied (Scheme 2). More basic amines reacted at room temperature, while weaker nucleophiles, such as aniline, at higher temperature and upon prolonged reaction time.

\footnotetext{
$\dagger$ This article belongs to the Special Issue devoted to the $85^{\text {th }}$ anniversary of Croatica Chemica Acta.

* Author to whom correspondence should be addressed. (E-mail: bzbz@pharma.hr)

* In memory of Ivan Butula (1932-2012).
} 


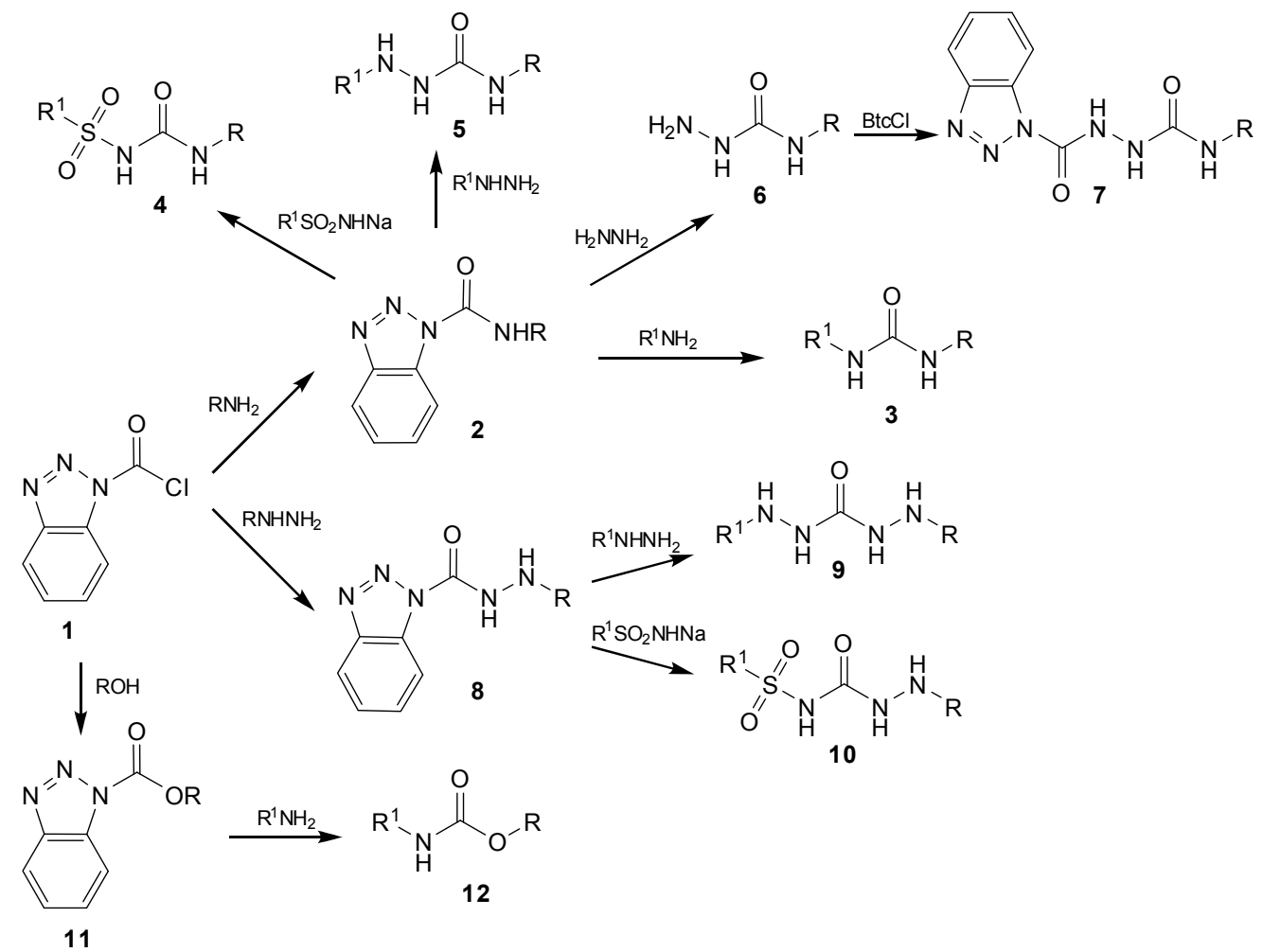

Scheme 2. Reactions of $\mathrm{BtcCl}$ with amino compounds and alcohols.

A number of symmetrical and asymmetrical ureas 3, sulfonylureas 4, semicarbazides 5 and 6, carbazides 9, sulfonylcarbazides 10 and carbamates 12 were prepared. ${ }^{3,13-16}$ Semicarbazide $\mathbf{6}$ reacted with another mole of chloride 1, affording 1-(1-benzotriazolecarbonyl)-4alkyl/arylsemicarbazides 7 . The reactions of $\mathrm{BtcCl}$ with amino compounds could be performed as one-pot reactions as well. In the first step chloride 1 reacted with one mole of amine (hydrazine) and compounds $\mathbf{2}$ or $\mathbf{8}$ were prepared. Upon addition of the second mole of the same or different amine (hydrazine), symmetrical or asymmetrical ureas $\mathbf{3}$ and carbazides $\mathbf{9}$ were obtained.

The analogous reactions were later on applied in the synthesis of non-steroidal antiinflammatory drugs (NSAID) semicarbazides, hydroxysemicarbazides and carbazides (discussed in the separate paragraph).

\section{SYNTHESIS OF BENZOXAZINE, QUINAZOLINE, TRIAZINE DERIVATIVES AND HYDROXYUREAS}

Synthesis of benzoxazine derivatives $\mathbf{1 5}$ and $\mathbf{1 6}$ and quinazoline derivative 19 started with reaction of chloride 1 with antranilic acid, through intermediates $\mathbf{1 3}$ and 14 (Scheme 3). ${ }^{17}$

Chloride 1 reacted with $N$-benzylhydroxylamine and gave 1-( $N$-benzyloxycarbamoyl)benzotriazole (2a). Benzyl group was removed by hydrogenolysis and the obtained product $\mathbf{2 b}$ was used for the synthesis of hydroxyurea derivatives 20. After heating, compound 2a dissociated into $N$-benzyloxycyanate (21), which trimerized to product $\mathbf{2 2}$. Hydrogenolysis of $\mathbf{2 2}$ gave trihydroxytriazinetrione 23 in quantitative yields. ${ }^{4}$

\section{SYNTHESIS OF AMINO ACID DERIVATIVES: HYDANTOINS, UREIDOAMIDES, OXADIAZINES}

The reaction of chloride $\mathbf{1}$ with amino acids enabled the use of benzotriazole both in peptide chemistry and in synthesis of hydantoins $\mathbf{2 8}$ and ureidoamides 29 and 30. ${ }^{18-21}$ The crucial intermediers $N$-(1-benzotriazolecarbonyl)-amino acids $\mathbf{2 4}$ were prepared from chloride $\mathbf{1}$ and two moles of amino acids and then transformed to the corresponding chlorides $\mathbf{2 5}$, esters 26 and amides $27 .{ }^{22}$ $N$-(1-benzotriazolecarbonyl)-amino acid amides 27 in alkaline medium or upon heating quantitatively cyclized to 3,5-disubstituted hydantoins (imidazolidine-2,4-diones) 28. The substituent at position 3 depended on the used amine, while substituent at position 5 originated from the amino acid. Hydrolysis of amides 27 under acidic conditions gave amino acid amides $32 .^{23}$ Benzotriazole moiety in compounds 27 was readily replaced with amines or hydroxylamines affording ureidoamides 29 and hydroxyureidoamides 30. ${ }^{24-26}$ Ureidoamides 31 were prepared directly from chlorides $\mathbf{2 5}$ with excess of 2aminoethanol, 3-aminopropanol and 5-aminopentanol. ${ }^{27}$ On the other hand, amidation of chlorides 25 with $N$-phenylhydroxylamine gave hydroxamic acids $\mathbf{3 3}$, which readily cyclized to oxadiazines 34 (Scheme 4). ${ }^{28}$ 

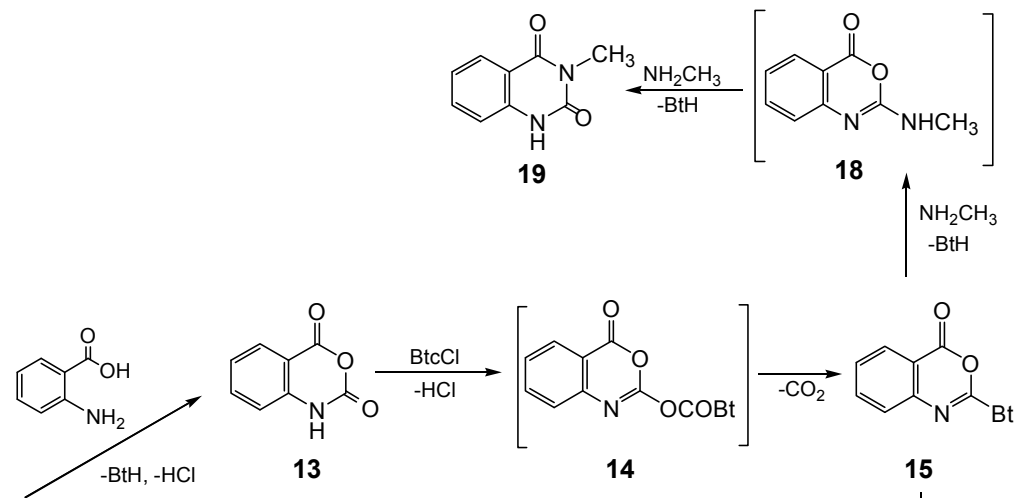

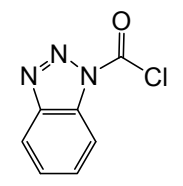

1
13 $\mathrm{NH}\left(\mathrm{C}_{2} \mathrm{H}_{5}\right)_{2}$<smiles>CCOC(=O)N(CC)CCC[B]N(CC)CCN(CC)CC</smiles>
17

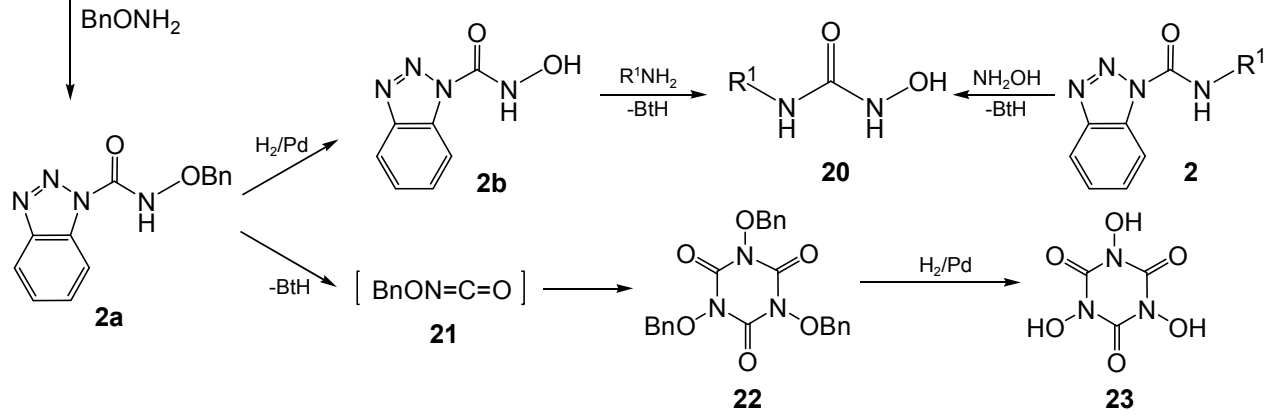

Scheme 3. Synthesis of benzoxazine, quinazoline, triazine derivatives and hydroxyureas.

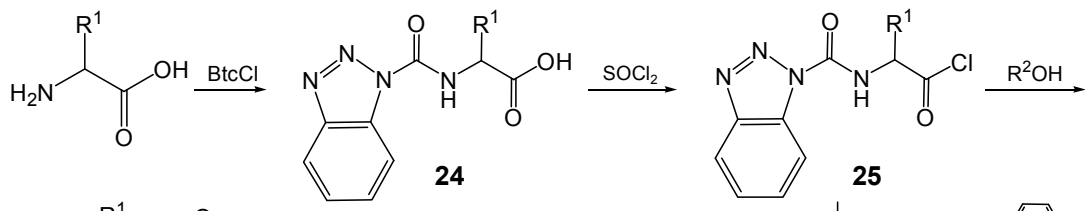<smiles>[R]OC(=O)C([R])NC(=O)n1nnc2ccccc21</smiles><smiles>[R]NC(=O)NC([R])C(=O)NC(=O)C([R1])NC(=O)N([R])[R]</smiles><smiles>[R]NC(=O)C([R])NCC(C)NC(=O)n1nnc2ccccc21</smiles>

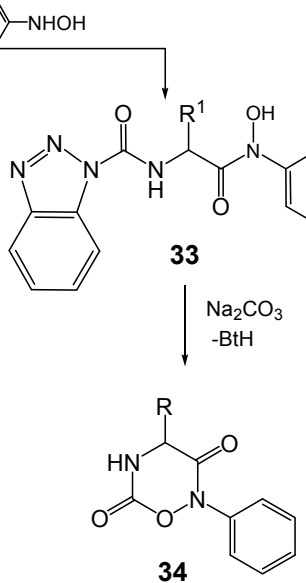

Scheme 4. Synthesis of amino acid derivatives: hydantoins, ureidoamides and oxadiazines. 


\section{SYNTHESIS OF OLYGOPEPTIDES}

$N$-(1-benzotriazolecarbonyl)-amino acids 24 were the starting compounds in the synthesis of amino acid, diand tripeptide derivatives. Btc group played a triple role in the peptide synthesis: $N$-protecting, $N$-activating and both $N$-protecting / $C$-activating role.

Removing of the Btc $N$-protecting group from amides $\mathbf{2 7}$ was performed in mild conditions, with trifluoroacetic acid or diluted $\mathrm{HCl}$ solution at room temperature, as it is already mentioned in the previous paragraph.

$N$-activating role of Btc group is outlined in Scheme $\mathrm{V}$, the line leading to compounds $\mathbf{3 8}^{23,29}$ This method of peptide bond formation is similar to methods described by Goldschmidt ${ }^{30}$ and Gante, ${ }^{31,32}$ which include reaction of $N$-protected amino acid with $\alpha$-isocyanoalkane acids. In our synthesis, unstable and toxic isocyano derivatives were replaced with $N$-Btc-amino acid esters 26 which upon heating dissociated to isocyanates and reacted with $\mathrm{N}$-protected amino acids, yielding peptide derivatives 38 in $60 \%$ average yields.

Double role of Btc group as $\mathrm{N}$-protecting/ $\mathrm{C}$-activating was observed in direct preparation of amino acid esters 42, amides 32, hydroxamic acids $\mathbf{4 3}$ and di- and tripeptides $\mathbf{4 0}$ from starting compounds $\mathbf{2 4}$ and corresponding alcohols, amines, hydroxylamines and amino acids or dipeptides (Scheme 5). ${ }^{23,25,29,33}$ The reactions proceeded through $N$-carboxy amino acids (NCA) intermediates 39. ${ }^{34}$

\section{SYNTHESIS OF NSAID DERIVATIVES}

NSAIDs and syntheses of their derivatives were heavily explored. NSAIDs contain carboxylic acid moiety, which makes them suitable for further derivatization. The reactions of NSAIDs with chloride $\mathbf{1}$ gave intermediate mixed anhydrides, which decarboxylated to NSAID benzotriazolides 44, stabile solids with activated carboxylic moiety. ${ }^{35}$ Compounds 44 readily reacted with a number of nucleophiles (alcohols, amines, hydroxylamines, hydrazine and polymers) under mild conditions yielding esters, ${ }^{35-37}$ amides 46, ${ }^{36,38-41}$ hydroxamic acid $\mathbf{4 7},{ }^{42,43}$ hydrazides $\mathbf{4 8},{ }^{44}$ hydroxyamides $\mathbf{4 9},{ }^{45}$ and polymer-NSAID and thiomer-NSAID conjugates $\mathbf{5 0}^{35,37,46-48}$ (for more information see the last paragraph). Ureidoamides $\mathbf{3 1}$ with two hydroxyl groups, reacted with two moles of NSAID-Bt $\mathbf{4 4}$ and gave esters 51 (Scheme 6). ${ }^{49}$

NSAID hydrazides 48 were the starting compounds for a number of further reactions. First, they reacted with 1-( $N$-alkyl/arylcarbamoyl)benzotriazoles $\mathbf{2}$, yielding 1-acyl-4-substituted semicarbazides $\mathbf{5 2}^{44}$ If the reaction was performed with 1-( $N$-benzyloxycarbamoyl)benzotriazole 2a, benzyloxysemicarbazides $\mathbf{5 3}$

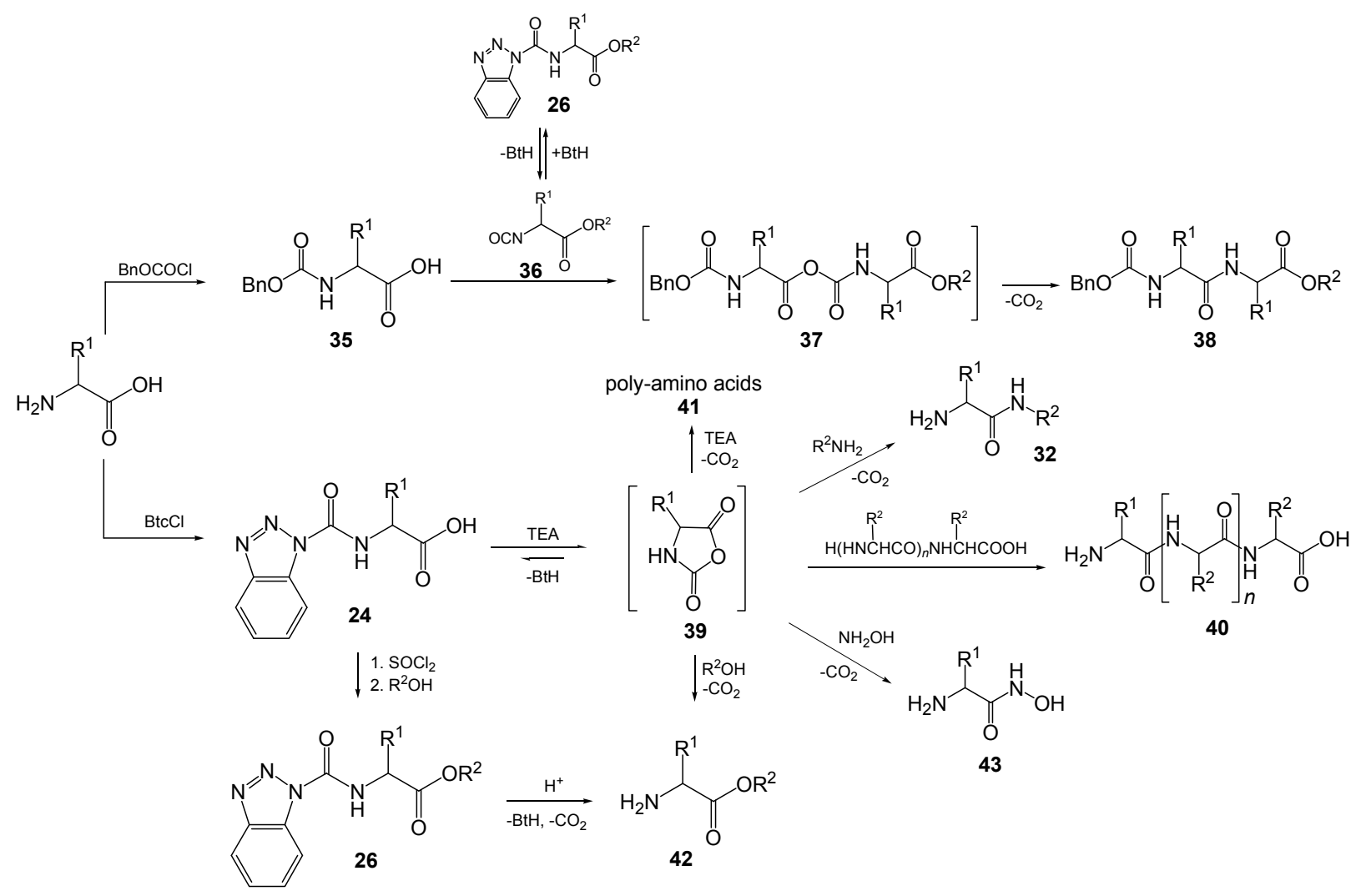

Scheme 5. Benzotriazolecarbonyl group as $N$-protecting, $N$-activating and both $N$-protecting/ $C$-activating group. 


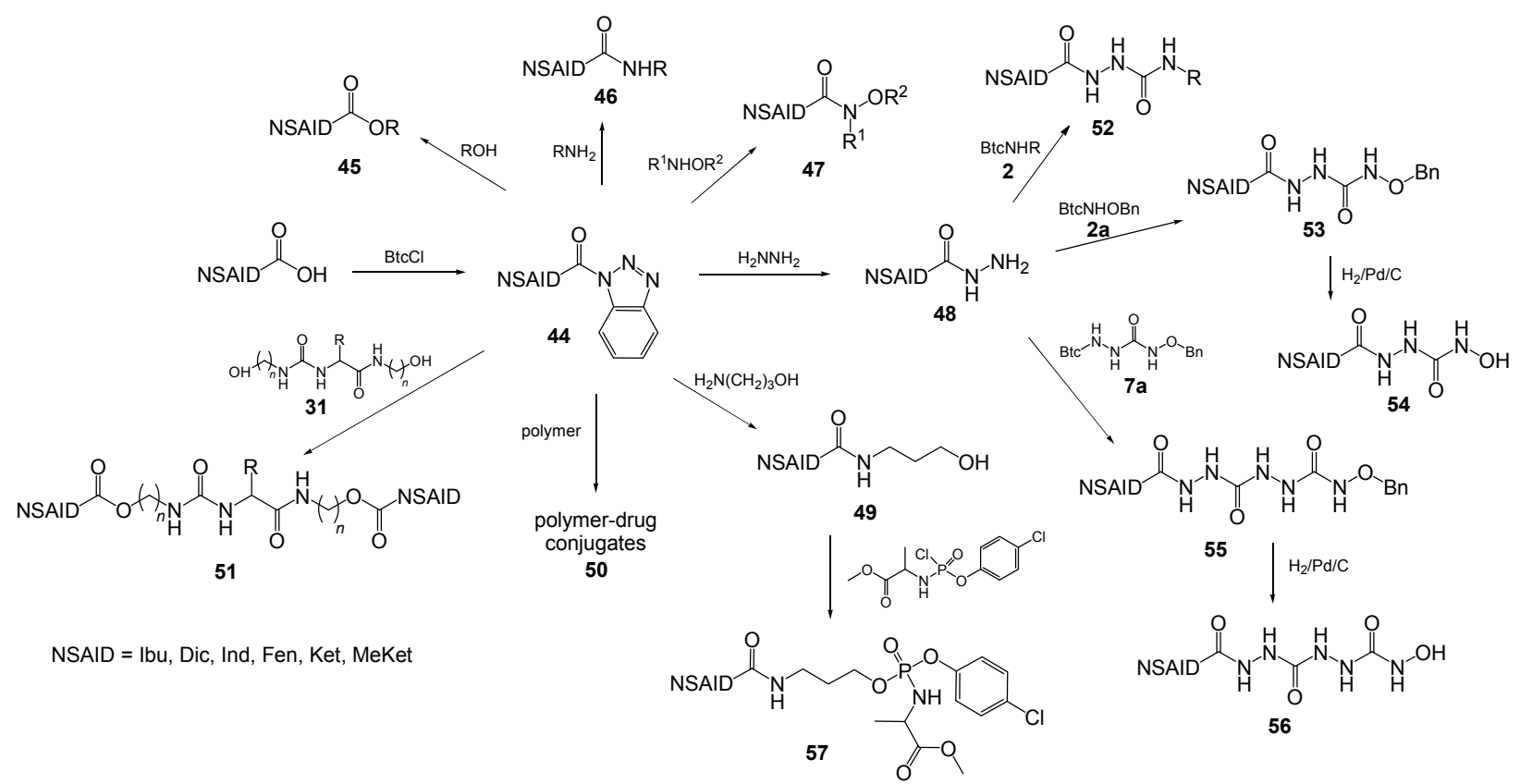

Scheme 6. Synthesis of NSAID derivatives.

were obtained, which after catalytic hydrogenation gave 1-acyl-4-hydroxysemicarbazides $54{ }^{44}$ 1-Acyl-5-substituted carbazides $\mathbf{5 5}$ were the products of the reaction of NSAID hydrazides 48 and 1-(1-benzotriazolecarbonyl)4-benzyloxysemicarbazide $\mathbf{7 a}{ }^{44}$ Their hydrogenation resulted in 1-acyl-5-hydroxycarbamoylcarbazides $\mathbf{5 6}{ }^{44}$

3-Hydroxypropanamides 49 were the starting materials for the reaction with $p$-chlorophenyl (methoxy-Lalanyl)phosphochloridate and the corresponding phosphoramidates 57 were obtained. ${ }^{45}$

\section{SYNTHESIS OF PRIMAQUINE DERIVATIVES}

Primaquine (PQ) is a well-known antimalarial drug and an interesting molecule for the derivatization in the search for potential pharmacological agents. ${ }^{50,51}$

Synthetic pathways towards PQ derivatives using benzotriazole as a synthetic auxiliary could be divided into two major routes. The first was the one in which $\mathrm{PQ}$ reacted with $\mathrm{BtcCl}$ yielding $\mathrm{PQ}$ benzotriazolide $\mathbf{5 8},{ }^{52}$ which was the starting material for the preparation<smiles>CCCCCCOc1cccc(C(C)C(=O)O)c1</smiles><smiles>CCCN(CCC)S(=O)(=O)c1ccc(C(=O)O)cc1</smiles>
diclofenac<smiles>Cc1ccc(C)c(OCCCC(C)(C)C(=O)O)c1</smiles><smiles>[R2]OC1CCC2C3CCc4cc([R20])ccc4C3CCC12C</smiles><smiles>COc1ccc2c(c1)c(CC(=O)O)c(C)n2C(=O)c1ccc(Cl)cc1</smiles><smiles>[R]=CC(=O)CCCCC</smiles>

Figure 1. Structures of the drugs used in preparation of polymer-drug conjugates. 


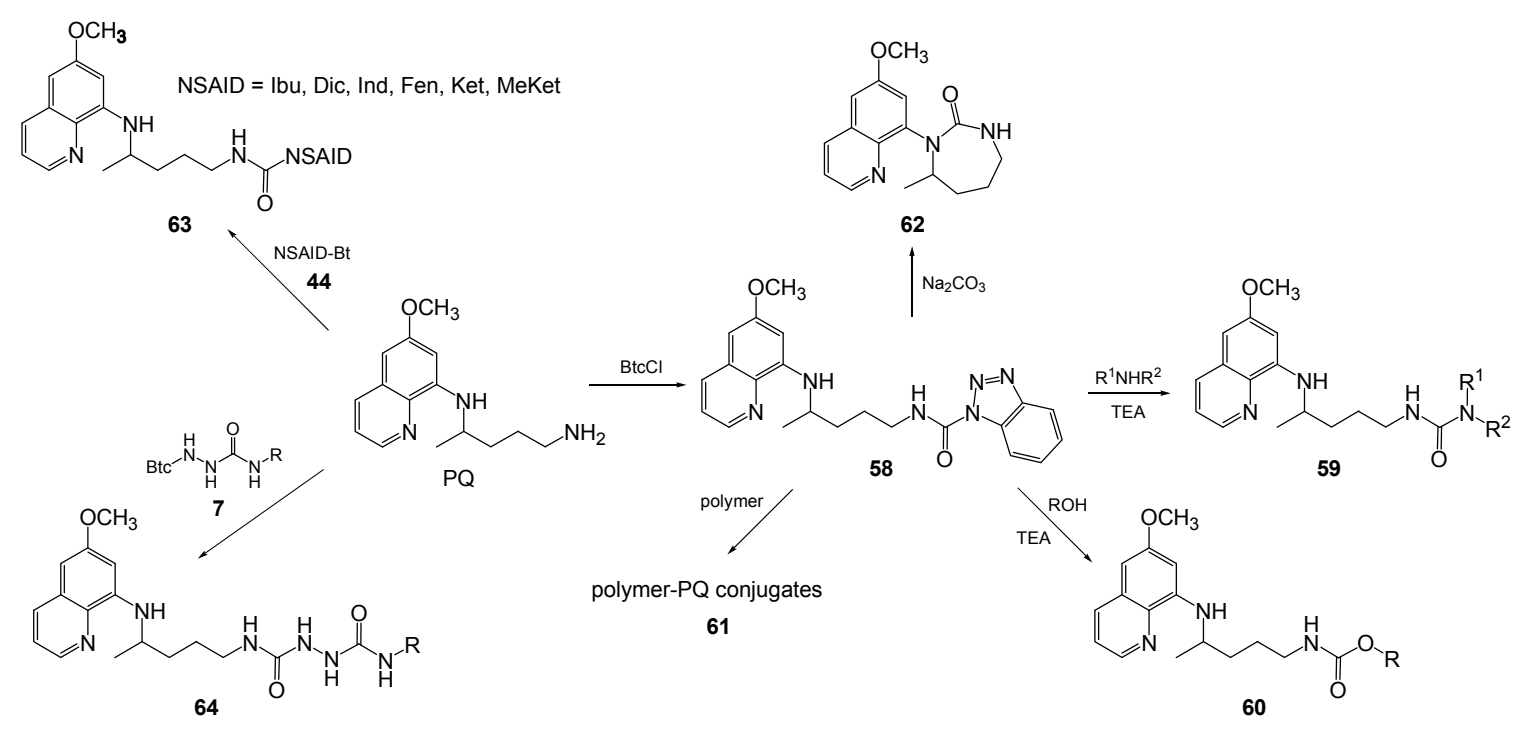

Scheme 7. Synthesis of primaquine derivatives.

of PQ ureas $59,{ }^{52}$ carbamates $\mathbf{6 0}^{53}$ and polymer-PQ conjugates 61. ${ }^{54}$ PQ ureas were obtained by aminolysis of benzotriazolide $\mathbf{5 8}$ with various amines, hydroxyamines and ethylenediamine, ${ }^{52,53}$ whereas PQ carbamates were prepared by the analogous reactions with alcohols. ${ }^{53}$ Diazepane derivative $\mathbf{6 2}$ was obtained by cyclization of PQ benzotriazolide in alkaline medium. ${ }^{53}$

The reaction of PQ benzotriazolide with two polymers, poly[ $\alpha, \beta-(N-2$-hydroxyethyl-DL-aspartamide) $]$ (PHEA) and poly[ $\alpha, \beta-(N-3$-hydroxypropyl-DL-aspartamide)] (PHPA), yielded two polymer-PQ conjugates 61. ${ }^{54}$ For more details on polymer-drug conjugates, see the next paragraph.

In the second pathway, PQ reacted as an primary amine with benzotriazole containing precursors, NSAID benzotriazolides 44 and 1-(1-benzotriazolecarbonyl)-4cycloalkyl/aryl semicarbazides 7 ; the former yielding NSAID-PQ twin drugs $63,{ }^{55}$ and the latter PQ semicarbazides $64 .^{56}$ Synthesis of primaquine derivatives is outlined in Scheme 7.

\section{SYNTHESIS OF POLYMER-DRUG CONJUGATES}

Benzotriazole was also applied in preparation of polymer-drug and thiomer-drug conjugates, polymeric prodrugs with drugs covalently bind to the polymeric carriers (Scheme 8 ). Binding of drugs from various therapeutic groups to polymers of polyaspartamide type by benzotriazolide method was performed and described in several papers. The following drugs were used: NSAIDs (ketoprofen, Ket, indomethacin, Ind, fenoprofen, Fen, diclofenac, Dic, ibuprofen, Ibu),,$^{35,37,46-48}$ antihyperlipemic (gemfibrozil, Gem), ${ }^{48,57,58}$ estrogens (estradiol benzoate, EB, estradiol valerate, EV), ${ }^{59,60}$ uricosuric (probenecid, Pro) ${ }^{36}$ and antimalarian drug primaquine, PQ. ${ }^{56}$ Structures of the drugs used in preparation of polymer-drug conjugates are presented in Figure 1.

Polymers of polyaspartamide type rich in hydroxyl and amino functionalities or thiomers bearing additional $\mathrm{SH}$ groups were prepared by aminolysis of poly-DL(2,5-dioxo-1,3-pyrrolidinediyl) (PSI) with 2-hydroxyethylamine, 3-hydroxypropylamine, ethylendiamine, cysteamine, methyl-(2-amino-4-mercapto)-butyrate or their combination, while PSI was prepared by thermal polycondensation of L-aspartic acid. The following polymers and copolymers were used in polymer-drug conjugate preparation: poly[ $\alpha, \beta-(N-2$-hydroxyethyl-DLaspartamide)] (PHEA), poly[ $\alpha, \beta-(N-3$-hydroxypropylDL-aspartamide)] (PHPA), poly $[\alpha, \beta-(N-2$-aminoethylDL-aspartamide)]-poly[ $\alpha, \beta-(N$-2-hydroxyethyl-DL-aspartamide)] copolymer (PAHA), poly $[\alpha, \beta-(N-2$-hydroxyethyl-DL-aspartamide) $]$-poly $[\alpha, \beta-(N-2$-thioethyl-DL-aspartamide)] (PHTA), poly $[\alpha, \beta-(N$-2-aminoethyl-DL-aspartamide $)]$-poly $[\alpha, \beta$ - $(N$-2-hydroxyethyl-DL-aspartamide $)]$ poly[ $\alpha, \beta-(N-3-m e r c a p t o-1-m e t h o x y c a r b o n y l-p r o p y l-D, L-$ aspartamide)] copolymer (PAHMA) or poly $[\alpha, \beta-(N-2-$ aminoethyl-DL-aspartamide $)]$-poly $[\alpha, \beta-(N-2$-hydroxyethyl-DL-aspartamide $)]$-poly[ $\alpha, \beta-(N-2$-thioethyl-DL-aspartamide)] copolymer (PAHTA).

In the first step, carboxyl or hydroxyl group of the drugs reacted with chloride $\mathbf{1}$, affording benzotriazolides $\mathbf{4 4}$ or active carbamates $\mathbf{6 5}$, which readily reacted with hydroxyl or amino groups of polymers and gave the polymer-drug conjugates $\mathbf{5 0 , 6 1}$ or $\mathbf{6 6} .^{35,37,46-48,56,57-60}$ With amino acids (glycine and $\beta$-alanine) or ethylenediamine derivatives $\mathbf{6 7}$ and $\mathbf{7 0}$ with additional functional group useful for further derivatization or binding to polymers were obtained and used in preparation of the 


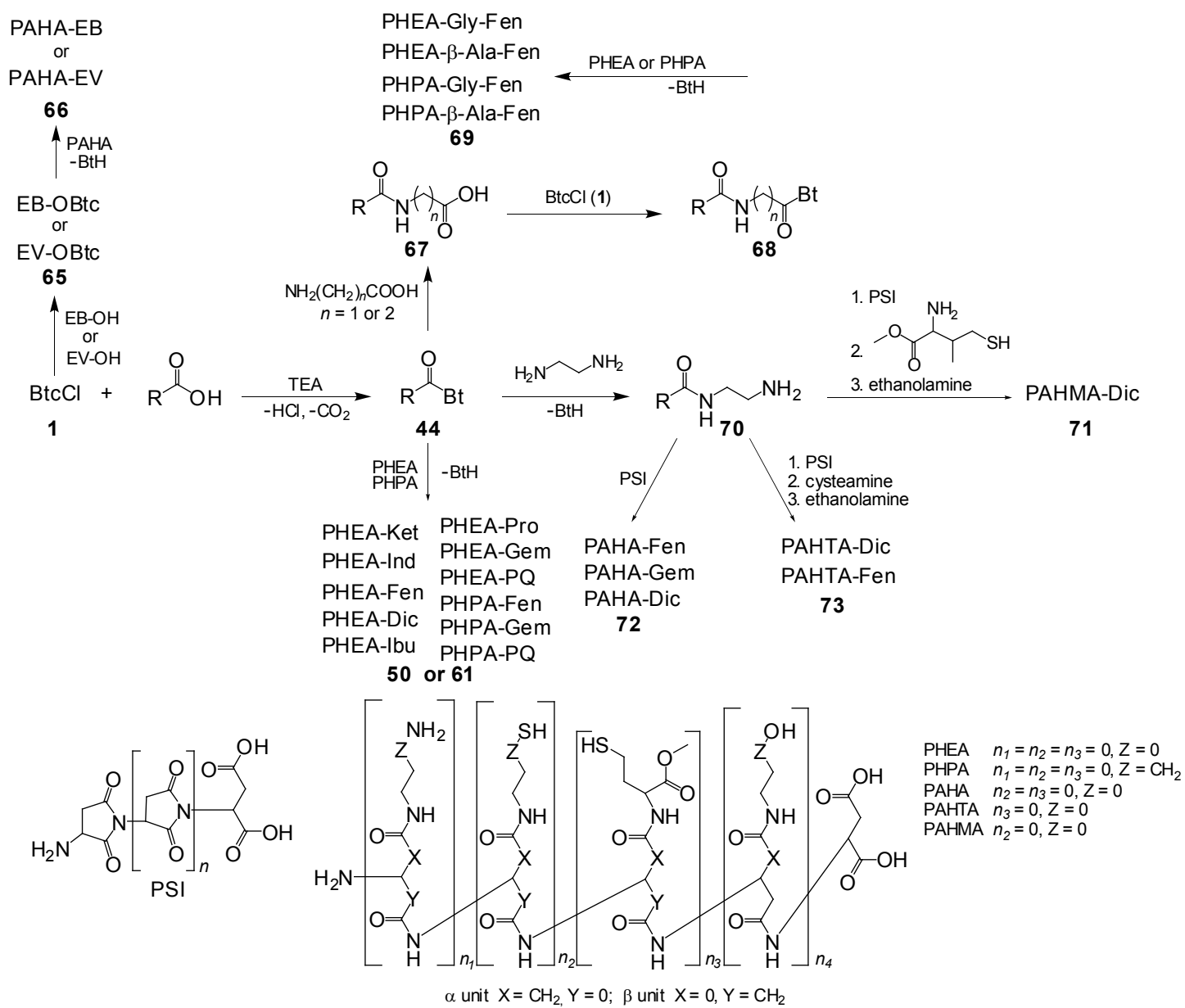

Scheme 8. Synthesis of polymer-drug conjugates.

conjugates with a spacer between polymer and drug. ${ }^{46,58}$ More than twenty polymer-drug conjugates were prepared, which differed in the polymer type, average molecular mass, bound drug, type of polymer-drug bond (ester, amide or carbamate), type of spacer and drugloading. Such macromolecular conjugates may offer many advantages compared to other drug delivery systems such as increased drug solubility, prolonged drug release, increased stability. It is also possible to accumulate drug at the site of the pathological process and to minimize its toxicity.

Acknowledgements. Support for this study by the Ministry of Science, Education and Sports of the Republic of Croatia (Projects No. 006-0000000-3216) is gratefully acknowledged.

\section{REFERENCES}

1. H. A. Staab, Angew. Chem. 74 (1962) 407-423

2. H. A. Staab, Chem. Ber. 89 (1956) 1927-1940.

3. I. Butula, M. V. Proštenik, and V. Vela, Croat. Chem. Acta 49 (1977) 837-842.

4. I. Butula and M. Jadrijević-Mladar Takač, Croat. Chem. Acta 73 (2000) 569-574.
5. A. R. Katritzky, S. Rachwal, and G. J. Hitchings, Tetrahedron 47 (1991) 2683-2732.

6. A. R. Katritzky, X. Lan, and W. Q. Fan, Synthesis (1994) 445-456.

7. A. R. Katritzky and B. Yang, J. Heterocyclic Chem. 33 (1996) 607-610.

8. A. R. Katritzky, H. Y. He, and K. Suzuki, J. Org. Chem. 65 (2000) 8210-8213.

9. A. R. Katritzky, N. Kirichenko, and B. V. Rogovoy, Arkivoc. 8 (2003) 8-14.

10. A. R. Katritzky, M. Yoshioka, T. Narindoshvili, A. Chung, and N. M. Khashab, Chem. Biol. Drug Des. 72 (2008) 182-188.

11. A. R. Katritzky M. El Khatib, O. Bol'shakov, L. Khelashvili, and P. J. Steel, J. Org. Chem. 75 (2010) 6532-6539.

12. A. R. Katritzky, X. Lan, J. Z. Yang, and O. V. Denisko, Chem. Rev. 98 (1998) 409-548.

13. I. Butula, M. Ćurković, M. V. Proštenik, V. Vela, and F. Zorko, Synthesis (1977) 704-706.

14. A. F. Hegarty, C. N. Hegarty, and F. L. Scoot, J. Chem. Soc. Perkin Trans. II (1975) 1166-1171.

15. I. Butula, V. Vela, and B. Ivezić, Croat. Chem. Acta 51 (1978) 339-346.

16. I. Butula, V. Vela, and M. V. Proštenik, Croat. Chem. Acta 52 (1979) 47-49.

17. I. Butula, V. Vela, and B. Zorc, Croat. Chem. Acta 54 (1981) 105-108.

18. B. Zorc, and I. Butula, Croat. Chem. Acta 54 (1981) 441-449. 
19. N. Opačić, M. Barbarić, B. Zorc, M. Cetina, A. Nagl, D. Frković, M. Kralj, K. Pavelić, J. Balzarini, G. Andrei, E. De Clerq, S Raić-Malić, and M. Mintas, J. Med. Chem. 48 (2005) 475-482.

20. N. Opačić, B. Zorc, M. Cetina, D. Mrvoš-Sermek, S. Raić-Malić, and M. Mintas, J. Peptide Res. 66 (2005) 85-93.

21. Z. Rajić, B. Zorc, S. Raić-Malić, K. Ester, M. Kralj, K. Pavelić, J. Balzarini, E. De Clercq, and M. Mintas, Molecules 11 (2006) 837-848.

22. I. Butula, B. Zorc, and V. Vela, Croat. Chem. Acta 54 (1981) 435-440.

23. B. Zorc, G. Karlović, and I. Butula, Croat. Chem. Acta 63 (1990) 565-578.

24. A. Al-Shamkhani, and R. Duncan, Int. J. Pharm. 122 (1995) 107-119.

25. I. Muskolaj, J. Matijević-Sosa, B. Zorc, and I. Butula, Acta Pharm. 47 (1997) 109-115.

26. I. Perković, I. Butula, B. Zorc, K. Hock, S. Kraljević Pavelić, K. Pavelić, E. De Clercq, J. Balzarini, and M. Mintas, Chem. Biol. Drug Des. 71 (2008) 546-553.

27. I. Perković, I. Butula, Z. Rajić, D. Hadjipavlou-Litina, E. Pontiki, and B. Zorc, Croat. Chem. Acta 83 (2010) 151-161.

28. M. Barbarić, S. Kraljević, M. Grce, and B. Zorc, Acta Pharm. 53 (2003) 175-186.

29. I. Butula, B. Zorc, M. Ljubić, and G. Karlović, Synthesis 4 (1983) 327-329

30. S. Goldschmidt, and M. Wick, Ann. Chem. 575 (1952) 217-231.

31. J. Gante, Angew. Chem. 78 (1966) 334.

32. J. Gante, Chem. Ber. 99 (1966) 2521-2525.

33. J. Matijević-Sosa, B. Zorc, and I. Butula, Croat. Chem. Acta 58 (1985) 239-243.

34. M. Zovko, I. Kalčić, B. Zorc, and I. Butula, Croat. Chem. Acta 76 (2003) 229-233.

35. B. Zorc, S. Antolić, I. Butula, Acta Pharm. 43 (1993) 127-133.

36. M. Lovrek, M. Jadrijević-Mladar Takač, B. Zorc, and B. Boneschans, Die Pharmazie 55 (2000) 811-816.

37. B. Zorc, and I. Butula, Acta Pharm. 44 (1994) 103-108.

38. M. Zovko, B. Zorc, M. Jadrijević-Mladar Takač, B. Metelko, and P. Novak, Croat. Chem. Acta 76 (2003) 335-341.

39. M. Zovko, B. Zorc, M. Jadrijević-Mladar Takač, and D. Zorc, Acta Pharm. 51 (2001) 107-115.

40. M. Marjanović, B. Zorc, L. Pejnović, M. Zovko, and M. Kralj, Chem. Biol. Drug Des. 69 (2007) 222-226.

41. Z. Rajić, D. Hadjipavlou-Litina, E. Pontiki, M. Kralj, L. Šuman, and B. Zorc, Chem. Biol. Drug Des. 75 (2010) 641-652.

42. Z. Rajić, I. Butula, B. Zorc, S. Kraljević Pavelić, K. Hock,
K. Pavelić, L. Naesens, E. De Clercq, J. Balzarini, M. Przyborowska, T. Ossowski, and M. Mintas, Chem. Biol. Drug Des. 73 (3) (2009) 328-338.

43. Z. Rajić, I. Perković, I. Butula, B. Zorc, D. Hadjipavlou-Litina, E. Pontiki, S. Pepeljnjak, and I. Kosalec, J. Enzyme Inhib. Med. Chem. 24 (2009) 1179-1187.

44. I. Perković, I. Butula, M. Kralj, I. Martin-Kleiner, J. Balzarini, D. Hadjipavlou-Litina, A-M. Katsori, and B. Zorc, Eur. J. Med. Chem. 51 (2012) 227-238.

45. K. Wittine, K. Benci, Z. Rajić, B. Zorc, M. Kralj, M. Marjanović, K. Pavelić, E. De Clercq, G. Andrei, R. Snoeck, J. Balzarini, and M. Mintas, Eur. J. Med. Chem. 44 (2009) 143-151.

46. M. Zovko, B. Zorc, M. Lovrek, and B. Boneschans, Int. J. Pharm. 228 (2001) 129-138.

47. M. Barbarić, M. Kralj, M. Marjanović, I. Husnjak, K. Pavelić, J. Filipović-Grčić, D. Zorc, and B. Zorc, Eur. J. Med. Chem. 42 (1) (2007) 20-29.

48. M. Zovko, M. Barbarić, B. Zorc, A. Hafner, and J. FilipovićGrčić, Acta Pharm. 55 (2005) 169-176.

49. I. Perković, Z. Rajić, and B. Zorc, S. African. J. Chem. (2013) Ahead of Print.

50. M. Jain, S. Vangapandu, S. Sachdeva, S. Singh, P. P. Singh, G. B. Jena, K. Tikoo, P. Ramarao, C. L. Kaul, and R. Jain, J. Med Chem. 47 (2004) 285-287.

51. P. M. O'Neill, R. C. Stoor, and B. K. Park, Tetrahedron 54 (1998) 4615-4622

52. G. Džimbeg, B. Zorc, M. Kralj, K. Ester, K. Pavelić, J. Balzarini, E. De Clercq, and M. Mintas, Eur. J. Med. Chem. 43 (2008) 1180-1187.

53. M. Šimunović, I. Perković, B. Zorc, K. Ester, M. Kralj, D. Hadjipavlou-Litina and E. Pontiki, Bioorg. Med. Chem. 17 (2009) 5605-5613.

54. Z. Rajić, G. Kos, B. Zorc, P. P. Singh, and S. Singh, Acta Pharm. 59 (2009) 107-115.

55. Z. Rajić, M. Zovko Končić, K. Miloloža, I. Perković, I. Butula, F. Bucar, and B. Zorc, Acta Pharm. 60 (2010) 325-337.

56. I. Perković, S. Tršinar, J. Žanetić, M. Kralj, I. Martin-Kleiner, J. Balzarini, D. Hadjipavlou-Litina, A. M. Katsori, and B. Zorc, J. Enzyme Inhib. Med. Chem. (2012) Ahead of Print.

57. M. Lovrek, M. Jadrijević-Mladar Takač, B. Zorc, B. Boneschans, Die Pharmazie 55 (2000) 811-816.

58. M. Lovrek, B. Zorc, B. Boneschans, and I. Butula, Int. J. Pharm. 200 (2000) 59-66.

59. M. Zovko, B. Zorc, P. Novak, P. Tepeš, B. Cetina-Čižmek, and M. Horvat, Int. J. Pharm. 285 (2004) 35-41.

60. M. Zovko, B. Zorc, and P. Novak, Acta Pharm. 61 (2011) 465-472. 